\title{
Evidence for Adult Lung Growth in Humans
}

\section{Citation}

Butler, James P., Stephen H. Loring, Samuel Patz, Akira Tsuda, Dmitriy A. Yablonskiy, and Steven J. Mentzer. 2012. "Evidence for Adult Lung Growth in Humans." New England Journal of Medicine 367 (3) (July 19): 244-247. doi:10.1056/nejmoa1203983.

\section{Published Version}

doi:10.1056/NEJMoa1203983

\section{Permanent link}

http://nrs.harvard.edu/urn-3:HUL.InstRepos:32631103

\section{Terms of Use}

This article was downloaded from Harvard University's DASH repository, and is made available under the terms and conditions applicable to Other Posted Material, as set forth at http:// nrs.harvard.edu/urn-3:HUL.InstRepos:dash.current.terms-of-use\#LAA

\section{Share Your Story}

The Harvard community has made this article openly available.

Please share how this access benefits you. Submit a story.

\section{Accessibility}




\title{
Evidence for Adult Lung Growth in Humans
}

\author{
James P. Butler, Ph.D., Stephen H. Loring, M.D., Samuel Patz, Ph.D., \\ Akira Tsuda, Ph.D., Dmitriy A. Yablonskiy, Ph.D., and Steven J. Mentzer, M.D.
}

\section{SUMMARY}

From the Division of Sleep Disorders (J.P.B.), Department of Radiology (J.P.B., S.P.), and the Division of Thoracic Surgery, Department of Surgery (S.J.M.), Brigham and Women's Hospital and Harvard Medical School; the Department of Environmental Health, Harvard School of Public Health (J.P.B., A.T.); and the Department of Anesthesia and Critical Care, Beth Israel Deaconess Medical Center and Harvard Medical School (S.H.L.) - all in Boston; and the Department of Radiology, Washington University, St. Louis (D.A.Y.). Address reprint requests to Dr. Mentzer at the Division of Thoracic Surgery, Brigham and Women's Hospital, 75 Francis St., Rm. 259, Boston, MA 02115, or at smentzer@partners.org.

N Engl J Med 2012;367:244-7. DOI: 10.1056/NEJMoa1203983

Copyright (c) 2012 Massachusetts Medical Society.
A 33-year-old woman underwent a right-sided pneumonectomy in 1995 for treatment of a lung adenocarcinoma. As expected, there was an abrupt decrease in her vital capacity, but unexpectedly, it increased during the subsequent 15 years. Serial computed tomographic (CT) scans showed progressive enlargement of the remaining left lung and an increase in tissue density. Magnetic resonance imaging (MRI) with the use of hyperpolarized helium-3 gas showed overall acinar-airway dimensions that were consistent with an increase in the alveolar number rather than the enlargement of existing alveoli, but the alveoli in the growing lung were shallower than in normal lungs. This study provides evidence that new lung growth can occur in an adult human.

OMPENSATORY LUNG GROWTH AFTER PNEUMONECTOMY HAS BEEN RECognized in many mammalian species. ${ }^{1}$ The prevailing concept has been that lung regeneration after pneumonectomy occurs in the young through the growth of new acinar units and alveoli, whereas in adult humans, parenchymal hyperexpansion and alveolar dilatation - not growth - are thought to occur. ${ }^{2}$ In young humans, lung growth has been documented by means of clinical observations and pulmonary-function studies. ${ }^{3-5}$ In adult humans, pulmonary-function studies have consistently shown that vital capacity after pneumonectomy is reduced to about half the predicted value for two lungs. ${ }^{6}$ Although there are no morphometric studies of human lungs after pneumonectomy, these results have been interpreted as supporting the absence of true growth in adult humans.

Experimental evidence has challenged the assumption that adult lungs do not grow. Studying adult dogs, Hsia et al. found a significant increase in alveolar surface area and capillary surface density after right-sided pneumonectomy. ${ }^{7}$ Recent highresolution CT studies in dogs indicate that lung growth after pneumonectomy correlates with regions of lobar stress and strain. ${ }^{8}$ In addition to suggesting the possibility of adult lung growth in humans, these studies have highlighted an important difference between the findings in larger animals and those in smaller animals (e.g., rodents) - namely, lung regeneration in the larger animals occurred on a time scale of months or years rather than days or weeks. We assessed lung growth over a period of 15 years in a woman who had undergone pneumonectomy.

CASE REPORT

In 1995, a 33-year-old woman underwent a right-sided pneumonectomy for treatment of a moderately differentiated hilar adenocarcinoma. She had a 32-pack-year 
history of cigarette smoking but had stopped smoking in 1994. Histologic examination of the tumor showed no inflammatory cells or peritumoral reaction. Before surgery, the forced expiratory volume in 1 second $\left(\mathrm{FEV}_{1}\right)$ and the forced vital capacity (FVC) were approximately $100 \%$ of her predicted values ${ }^{9}\left(\mathrm{FEV}_{1}\right.$ : 2.92 liters, $99.7 \%$ of the predicted value; FVC: 3.69 liters, $103.6 \%$ of the predicted value). After her surgery, the patient underwent four cycles of adjuvant chemotherapy with carboplatin and paclitaxel. Twelve weeks after the pneumonectomy, the $\mathrm{FEV}_{1}$ was 1.03 liters (35.2\% of the predicted value) and the FVC was 1.75 liters (49.1\% of the predicted value). Serial CT imaging at intervals of approximately 1 year showed progressive enlargement of the remaining lung (Fig. 1), with herniation of the left lung into the right hemithorax (Lung Herniation Index ${ }^{10}$ [LHI] score, 1.58; typical range, 1.00 to 1.50 , with higher values indicating increased herniation). Between 12 and 18 months after pneumonectomy, the patient had exertional symptoms that were consistent with postpneumonectomy syndrome. ${ }^{11}$ At 18 months after pneumonectomy (Fig. 2), a prosthetic volume expander, placed in the right postpneumonectomy space, provided relief from her dyspnea symptoms. The patient subsequently participated in a daily exercise program consisting of walking, cycling, and yoga. Recurrent symptoms 10 years later were associated with the rupture of the volume expander; the prosthesis was replaced, with subsequent improvement in the patient's symptoms.

RESULTS

During the 15-year follow-up period, spirometry showed a progressive increase in $\mathrm{FEV}_{1}$ (to 1.56 liters, $59.7 \%$ of the predicted value) and FVC (to 2.37 liters, $73.3 \%$ of the predicted value) - that is, a $51 \%$ increase in $\mathrm{FEV}_{1}$ and a $35 \%$ increase in FVC. These increases contrast with the patient's predicted age-related decrease in $\mathrm{FEV}_{1}(-11 \%)$ and FVC (-9\%). ${ }^{9}$ Esophageal manometry performed at 1 year and 14 years after pneumonectomy showed normal pulmonary compliance ( 0.135 to 0.150 liters per centimeter of water) and normal pulmonary resistance $(3.5$ to $6.0 \mathrm{~cm}$ of water per liter per second) for the single lung. Intrathoracic pressures after inhalation to maximal lung volume were markedly negative $(-71 \mathrm{~cm}$

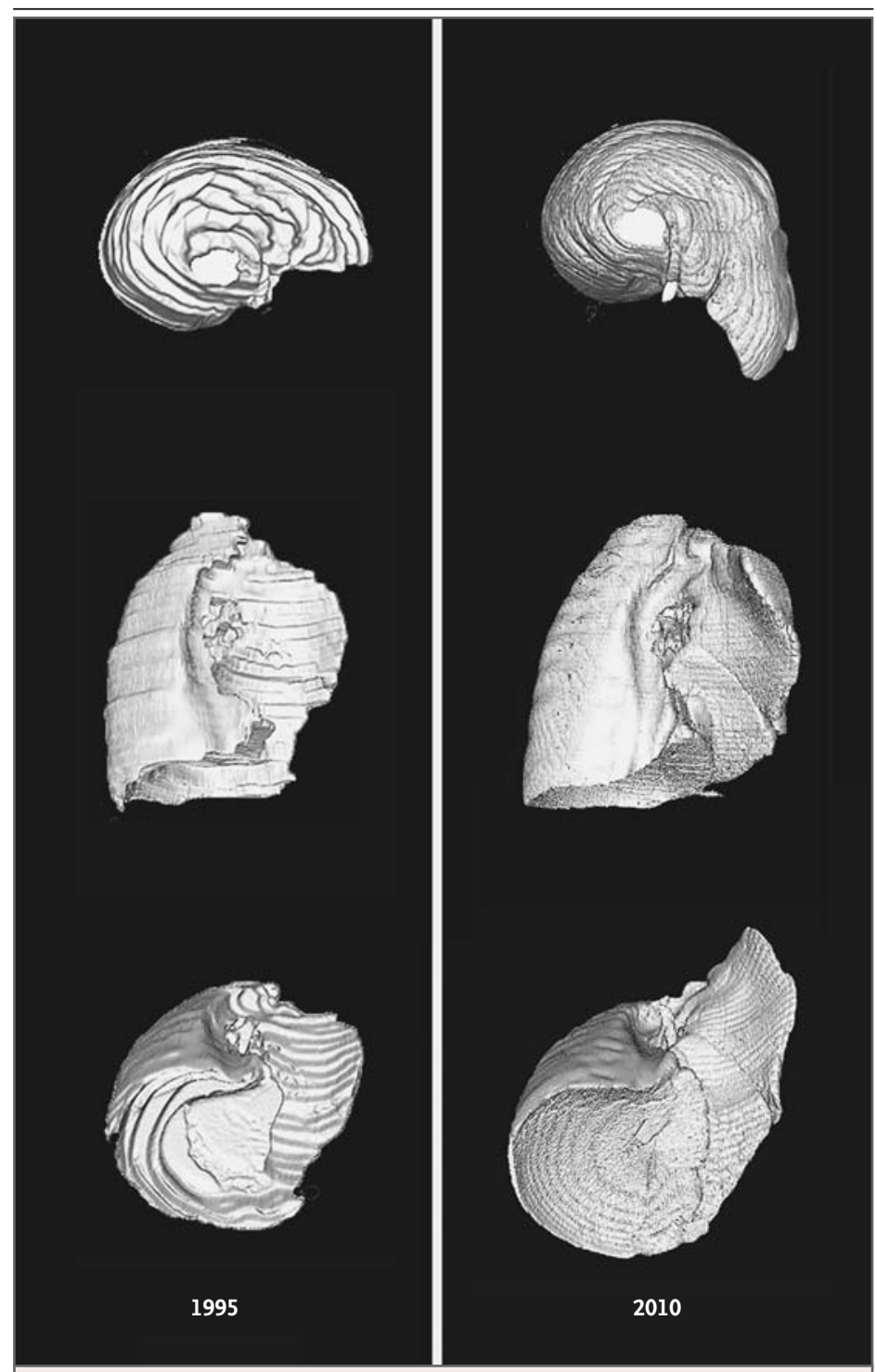

Figure 1. Three-Dimensional Reconstructions of Axial CT Images of the Left Lung after a Right-Sided Pneumonectomy.

The reconstructions, shown in three projections, are based on CT scans of contiguous 10-mm sections in 1995 and $5-\mathrm{mm}$ sections in 2010 and are presented with identical scaling.

of water), indicating a strong chest wall capable of high inspiratory force.

From the patient's serial surveillance CT scans, we measured the lung gas and tissue volumes over the 15-year interval. ${ }^{13-15}$ Voxel densities, measured by interpolation from densities in tracheal air and aortic blood, ${ }^{12}$ were summed to obtain overall measures of lung expansion and the separate contributions of gas and tissue vol- 


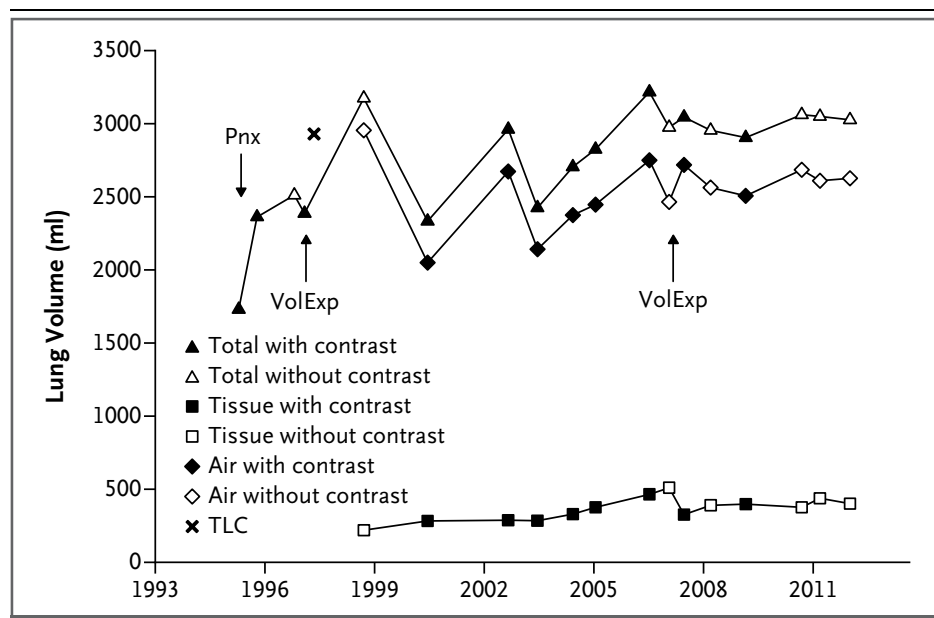

Figure 2. Air, Tissue, and Total Lung Volumes Based on CT Images of the Left Lung Obtained before and after Pneumonectomy.

Total lung volumes, as assessed by radiography, were fractionated into gas and tissue components. ${ }^{12}$ Data were obtained from CT scans with and without intravenous contrast material; one gas volume at total lung capacity (TLC) was measured by plethysmography. Early scans, digitized from radiographic film, permitted the measurement of total lung volume only. Within months after pneumonectomy (Pnx), the total lung volume increased and the lung density fell below normal (to $0.07 \mathrm{~g}$ per milliliter), suggesting simple hyperexpansion of the lung. Thereafter, the lung tissue volume progressively increased and the lung density returned to a level normally seen at full inspiration ( $0.13 \mathrm{~g}$ per milliliter), suggesting the growth of new lung tissue. Insertion of a volume expander (VolExp) in the right hemithorax on two occasions was followed by an increase in gas volume.
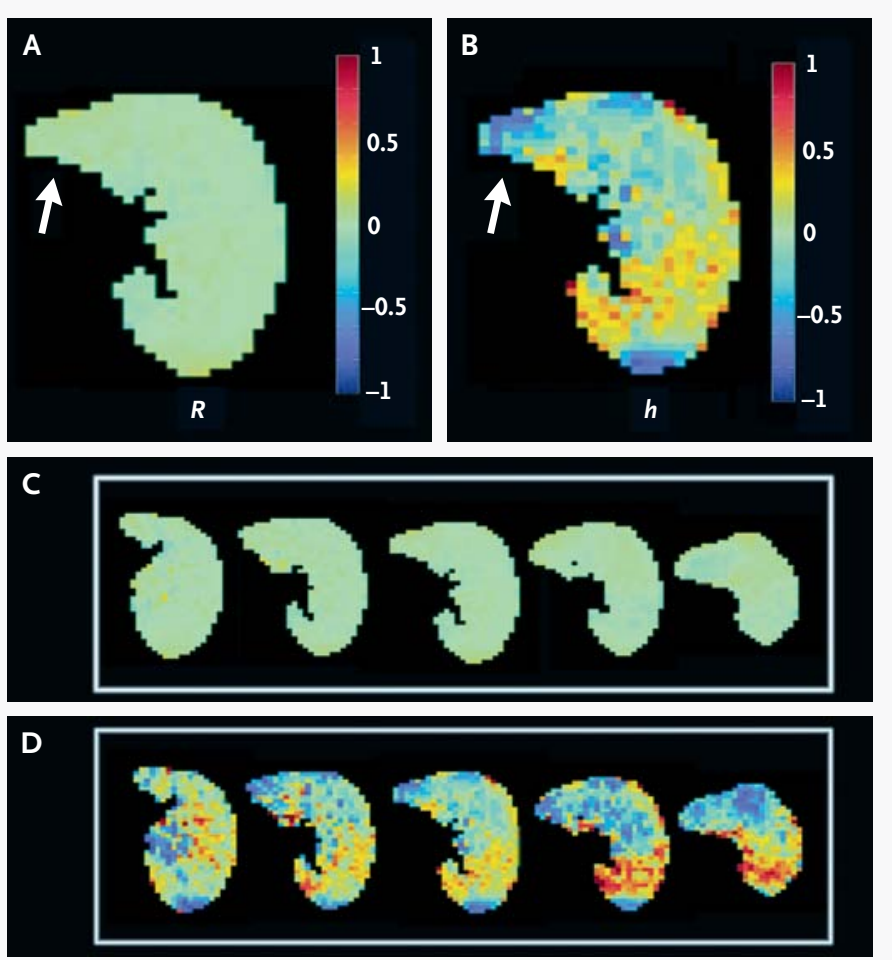

umes (Fig. 2). Both gas and total lung volumes rose rapidly to an approximate plateau; more important, there was a gradual and sustained rise in tissue volume - nearly doubling after the pneumonectomy.

In late 2010, we assessed lung microstructure with the use of MRI and hyperpolarized helium-3 gas on an investigational protocol. ${ }^{16}$ This approach, requiring only a brief breath hold for acquisition of an MRI scan after inhalation of helium-3 gas, measures the apparent diffusion of the inhaled gas. Studies in both animal models $^{17}$ and humans ${ }^{16}$ have shown that the diffusion characteristics of the helium-3 gas can be analyzed to derive a quantitative estimate of acinar microstructure. Two parameters were derived from the acquired images of voxel density versus magnetic-field gradient. The first was the radial dimension of the acinar airways $(R)$, under the assumption that the alveolar axial dimension is proportional to $R$; the second was the effective alveolar depth (h). ${ }^{16}$ In the absence of regeneration or growth of new septa after pneumonectomy, the shape stability of the lung predicts that $R$ will increase regionally as the lung expands into the pneumonectomy space - that is, there will be a systematic increase in $R$ in the region of lung herniating into the contralateral hemithorax.

In our patient, 15 years after pneumonectomy, the mean $( \pm S D) R(330 \pm 20 \mu \mathrm{m}$ over all voxels $)$ was essentially identical to $R$ in normal lungs ${ }^{18}$ $(322 \pm 21 \mu \mathrm{m})$. More notably, $\mathrm{R}$ was remarkably uniform, varying by less than $5 \%$ across the entire lung field (Fig. 3A and 3C). The alveolar depth (h) was $70 \pm 30 \mu \mathrm{m}$, which was significantly less than that in normal lungs $(138 \pm 22 \mu \mathrm{m}){ }^{18}$ In addition, the distribution of $h$ in this patient was

Figure 3. Acinar-Airway Dimensions on Transverse (Axial) Images Obtained with Hyperpolarized Helium-3 MRI in 2010.

Panel $A$ is a color map of the fractional deviations of the radial dimension of the acinar airway $(R)$ relative to its mean $R$ of $330 \mu \mathrm{m}$; similarly, Panel B shows the fractional deviations of the effective alveolar depth $(h)$ relative to its mean $h$ of $70 \mu \mathrm{m}$. Lung crossing the mid line is indicated by arrows. Panels $A$ and $B$ are the central slices from five sequential axial images of $R$ (Panel $C$ ) and $h$ (Panel D), with the same color scale. The helium-3 MRI scan shows remarkable uniformity in $R$, which varied by less than $5 \%$ over the entire lung field - a finding inconsistent with regional expansion into the right hemithorax but compatible with true growth. 
moderately more heterogeneous than in normal lungs (Fig. 3B and 3D).

\section{DISCUSSION}

The data supporting lung growth in this patient included increases in $\mathrm{FEV}_{1}, \mathrm{FVC}$, and CT-derived tissue volume. With respect to lung microstructure, diffusion MRI studies showed remarkable homogeneity in the acinar-airway dimensions (R). In addition, if the increased volume were associated with geometrically similar lung hyperexpansion alone, the volume increase of $77 \%$ during the 15 years after pneumonectomy would imply an increase in $R$ to $390 \mu \mathrm{m}$ - a value significantly higher than the $330 \mu \mathrm{m}$ observed in this patient. Together with the volume increase, the relatively normal value of $R$ implies a $64 \%$ increase in the number of alveoli. In contrast to $R$, the effective alveolar depth (h) was significantly shallower, and more heterogeneous, than in normal lungs. This heterogeneity may reflect structural distortion due to parenchymal stretch. The areas of greatest herniation in our patient exhibited the shallowest alveoli, a finding that is consistent with stretch-induced structural distortion. Alternatively, it is possible that regenerating alveoli in adults - regardless of the stretch distribution - exhibit a shallow alveolar structure.

Several characteristics of this patient may be relevant to lung growth: her relatively young age at the time of pneumonectomy, the degree of parenchymal hyperexpansion (including postpneumonectomy syndrome), and her daily exercise program. We speculate that these characteristics facilitated the stretch of the lung exposed to the pneumonectomy space. We hypothesize that, reminiscent of the role of stretch in lung development, ${ }^{19}$ cyclic stretch as such may be an important trigger for new lung growth. Regardless of the specific mechanism, the findings in this patient support the concept that new lung growth can occur in adult humans.

Supported in part by grants from the National Institutes of Health (R01 HL094567, R01 HL096471, R01 HL070037, R01 HL054885, and R01 HL52586).

Disclosure forms provided by the authors are available with the full text of this article at NEJM.org.

We thank J.D. Quirk, I. Muradyan, E. Millet, and A. Novero for assistance with data analysis and Matlab image processing; D.S. Gierada for facilitation of the hyperpolarized helium-3 MRI studies; and F.G. Hoppin, Jr., for helpful conceptual contributions.
REFERENCES

1. American Thoracic Society. Mechanisms and limits of induced postnatal lung growth. Am J Respir Crit Care Med 2004;170:319-43.

2. Bremer JL. The fate of the remaining lung tissue after lobectomy or pneumonectomy. J Thorac Surg 1936;6:336-43.

3. Peters RM, Wilcox BR, Schultz EH Jr. Pulmonary resection in children: longterm effect on function and lung growth. Ann Surg 1964;159:652-60.

4. Stiles QR, Meyer BW, Lindesmith GG, Jones JC. The effects of pneumonectomy in children. J Thorac Cardiovasc Surg 1969; 58:394-400.

5. Laros CD, Westermann CJJ. Dilatation, compensatory growth, or both after pneumonectomy during childhood and adolescence: a thirty-year follow-up-study. J Thorac Cardiovasc Surg 1987;93:570-6.

6. Gaensler EA, Strieder JW. Progressive changes in pulmonary function after pneumonectomy: the influence of thoracoplasty, pneumothorax, oleothorax, and plastic sponge plombage on the side of pneumonectomy. J Thorac Surg 1951;22: 1-34.

7. Hsia CCW, Herazo LF, Fryder-Doffey

F, Weibel ER. Compensatory lung growth occurs in adult dogs after right pneumonectomy. J Clin Invest 1994;94: 405-12.

8. Yilmaz C, Tustison NJ, Dane DM, et al. Progressive adaptation in regional parenchyma mechanics following extensive lung resection assessed by functional computed tomography. J Appl Physiol 2011;111: 1150-8.

9. Knudson RJ, Slatin RC, Lebowitz MD, Burrows B. Maximal expiratory flow-volume curve: normal standards, variability, and effects of age. Am Rev Respir Dis 1976;113:587-600.

10. Fujimoto T, Matsui T, Hanawa T, et al. Lung herniation as an anatomic consequence of pneumonectomy. Thorac Cardiovasc Surg 2002;50:292-5.

11. Kopec SE, Irwin RS, Umali-Torres CB, Balikian JP, Conlan AA. The postpneumonectomy state. Chest 1998;114:1158-84. 12. O'Donnell CR, Bankier AA, Stiebellehner L, Reilly JJ, Brown R, Loring SH. Comparison of plethysmographic and helium dilution lung volumes: which is best for COPD? Chest 2010;137:1108-15.

13. Coxson HO, Mayo JR, Behzad H, et al. Measurement of lung expansion with computed tomography and comparison with quantitative histology. J Appl Physiol 1995;79:1525-30.
14. de Jong PA, Nakano Y, Lequin MH, et al. Estimation of lung growth using computed tomography. Eur Respir J 2003;22: 235-8.

15. de Jong PA, Long FR, Wong JC, et al. Computed tomographic estimation of lung dimensions throughout the growth period. Eur Respir J 2006;27:261-7.

16. Yablonskiy DA, Sukstanskii AL, Woods JC, et al. Quantification of lung microstructure with hyperpolarized He-3 diffusion MRI. J Appl Physiol 2009;107:125865.

17. Osmanagic E, Sukstanskii AL, Quirk JD, et al. Quantitative assessment of lung microstructure in healthy mice using an MR-based He-3 lung morphometry technique. J Appl Physiol 2010;109:1592-9.

18. Hajari AJ, Yablonskiy DA, Sukstanskii AL, Quirk JD, Conradi MS, Woods JC. Morphometric changes in the human pulmonary acinus during inflation. J Appl Physiol 2012;112:937-43.

19. Brody JS, Thurlbeck WM. Development, growth, and aging of the lung. In: Macklem PT, Mead J, eds. Handbook of physiology — the respiratory system: mechanics of breathing. Bethesda, MD: American Physiological Society, 1986:355-86. Copyright (c) 2012 Massachusetts Medical Society. 